\title{
RANDOM CHARACTERISTICS OF RUNOFF COEFFICIENT IN URBAN CATCHMENTS
}

\author{
G. Becciu and A. Paoletti
}

Dipartimento di Ingegneria Idraulica, Ambientale e del Rilevamento, Politecnico di Milano, Piazza

Leonardo da Vinci 32 - 20133 Milano, Italy

\begin{abstract}
In the paper an analysis of hydrological losses, observed during storm events recorded in experimental urban catchments, is presented. Random nature of runoff coefficient and its effects on peak discharge estimation are discussed. Simple relationships for estimation of main moments of runoff coefficient are presented.
\end{abstract}

\section{KEYWORDS}

Runoff coefficient; hydrological losses; rainfall-runoff models.

\section{INTRODUCTION}

In urban catchments the hydrological losses due to evaporation and interception of vegetation are usually neglected in comparison with those due to depression storages and, mainly, infiltration. Only these two last losses are normally taken into consideration in rainfall-runoff models, even in the physically based ones, with different procedures according to the types of surface present in the basin. Accumulation in surface depressions happens all over the catchment and does not amount to much more than a few millimetres, with rather more in permeable or low gradient areas. Infiltration effect is normally calculated only in permeable areas, assuming that the losses in areas considered impermeable such as roofs, roads, paved areas, etc., are negligible.

From these approaches it follows that the runoff coefficient $\varphi$, the ratio between the surface runoff collected by the drainage network and the rainfall volume, varies in each event but in any case is similar to the coefficient of impermeability Imp, the ratio between the impermeable areas connected to the drainage system and the overall area, when the storm intensity is lower than the infiltration velocity of unpaved areas, or it is higher than Imp when the storm intensity overcomes the infiltration velocity. This result is not apparent in the numerous experimental data now available for urban basins all over the world and in Italy. In fact the experimental values of $\varphi$ usually vary greatly within a catchment and are almost always less than Imp. For example, the data on 150 events accurately recorded in eight different Italian urban areas, show that only in very few events, and these all in northern Italian catchments, did the value of $\varphi$ exceed $\operatorname{Imp}$ (Calomino and Paoletti, 1994). The coefficient $\varphi$ is often well below Imp even when the rainfall was considerable, showing that losses in "impermeable" areas are not negligible and that there are loss mechanisms different from those included in the above mentioned simple schemes. Moreover, even the $\operatorname{Imp}$ value is uncertain because of the difficulty of identifying the impervious areas effectively connected to the drainage system.

Analysis of experimental data clearly demonstrates that the phenomenon is more complex and that its natural variations cannot be adequately explained by using an approach that is purely deterministic. On the other hand it has to be noted that, in design problems, the need to estimate the hydrological losses in urban catchments is mainly concerned with the probabilistic estimation of the peak discharge in the drainage network.

Therefore it seems best to follow, as for other hydrological phenomena, a probabilistic approach in which the hydrological loss, considered in a global way without a separate estimation of their components, is treated as 
a random variable. Following this approach, the peak discharge $Q$ in the outlet of a catchment subject to a rainfall $i(t)$, which is given by the well-known rational formula:

$$
Q=\varepsilon\left(\theta_{c}\right) \varphi i_{m}\left(\theta_{\partial}\right) A
$$

or in probabilistic form

$$
Q(T)=A I(T),
$$

where $A=$ catchment area

$\varepsilon\left(\theta_{c}\right)=$ coefficient $(\leq 1)$ depending on the rainfall-runoff model

$i_{m}\left(\theta_{c}\right)=$ constant rainfall intensity for the duration $\theta_{c}$

$\varphi=$ runoff coefficient

$\theta_{c}=$ critical rainfall duration, for which $Q$ is maximum

$I=\varepsilon\left(\theta_{c}\right) \varphi i_{m}\left(\theta_{c}\right)$

$T=$ return period

can be regarded as a random variable function of other random variables. Assuming that the duration $\theta_{c}$ is functionally related to catchment, model and rainfall characteristics, the random nature of $Q$ depends only on those of intensity $i_{m}\left(\theta_{c}\right)$ and runoff coefficient $\varphi$. In engineering practice, the fact that $\varphi$ is a random variable is commonly taken into account estimating, erroneously, the value of peak discharge as $Q(T)=\varepsilon\left(\theta_{c}\right) \varphi(T)$ $i_{m}\left(T, \theta_{c}\right) A$, without considering the joint probability distribution of the variables. A correct and, at the same time, simple approach to the problem is estimating the main two moments of the distribution of $Q$ that can be expressed, in a first-order approximation, as functions of the corresponding moments of $i_{m}\left(\theta_{c}\right)$ and $\varphi$, according to the following equations (Kapur and Lamberson, 1977):

$$
\begin{aligned}
& \mu_{Q}=\varepsilon A \mu_{i} \mu_{\varphi} \\
& \sigma_{Q}^{2}=\varepsilon^{2} A^{2}\left(\mu_{i}^{2} \sigma_{\varphi}^{2}+\mu_{\varphi}^{2} \sigma_{i}^{2}+2 \rho_{i \varphi} \mu_{i} \mu_{\varphi} \sigma_{i} \sigma_{\varphi}\right)
\end{aligned}
$$

where $\mu_{Q}, \mu_{i}, \mu_{\varphi}$ and $\sigma_{Q}, \sigma_{i}, \sigma_{\varphi}$ are the means and the standard deviations of $Q, i_{m}\left(\theta_{c}\right)$ and $\varphi$, while $\rho_{\mathrm{i} \varphi}$ is the correlation coefficient between $i_{m}\left(\theta_{c}\right)$ and $\varphi$.

While there are usually enough data for the estimation of the moments of rainfall intensity $\mu_{i}, \sigma_{i}$, this rarely happens for the moments of the runoff coefficient. In this paper a procedure for estimating $\mu_{\varphi}$, $\sigma_{\varphi}$, developed from analysis of recorded data in experimental catchments all over the world, is proposed.

\section{HYDROLOGICAL LOSSES IN EXPERIMENTAL URBAN CATCHMENTS}

The data of 312 events recorded in 20 selected experimental urban catchments, 12 reported by Maksimovic and Radojkovic (1986) and 8 (Italian) by Calomino and Paoletti (1994), were used in the analysis. In table 1 the main characteristics of these catchments and events are reported.

Analysing the total losses observed in the 312 events, some common features of the phenomenon were noted, despite the different climatic conditions of the sites and characteristics of the catchments. Firstly, the variability of the loss depth $L$ for different events in the same catchment is significantly less than that, usually high, of the runoff coefficient $\varphi$. Secondly, in all catchments a very strong functional relationship between loss depth $L$ and rainfall depth $h$, of the type

$$
L=L_{0}+\alpha h^{\beta} \quad[\mathrm{mm}]
$$

can be observed. The best values for the parameters $L_{o}, \alpha$ and $\beta$ are reported in Table 1 ; in Fig. 1 the best and 
worst correlation cases are shown. This result can be interpreted by assuming that $L$ is due mainly to infiltration, also in the "impermeable" areas, and, in a lesser way, to other phenomena that cause an initial loss $L_{0}$, independent from storm characteristics, often called "initial abstraction".

Table 1. Main characteristics of selected experimental catchments and events: (1) from Maksimovic and Radojkovic (1986); (2) from Calomino and Paoletti (1994).

\begin{tabular}{|l|c|c|c|c|c|c|c|c|}
\hline $\begin{array}{l}\text { Catchment name } \\
\text { and code }\end{array}$ & $\begin{array}{c}A \\
{\left[10^{4} \cdot \mathrm{m}^{2}\right]}\end{array}$ & Imp & $\begin{array}{c}n^{\circ} \\
\text { events }\end{array}$ & $\begin{array}{c}\text { Rainfall } \\
\text { depth range } \\
{[\mathrm{mm}]}\end{array}$ & $\varphi$ range & $\begin{array}{c}L_{O} \\
{[\mathrm{~mm}]}\end{array}$ & $\alpha$ & $\beta$ \\
\hline IT01 Luzzi (1) (2) & 1.89 & 0.913 & 25 & $1.4-22.6$ & $0.46-0.81$ & 0.00 & 0.30 & 1.07 \\
\hline IT02 Parco d'Orleans (2) & 14.29 & 0.700 & 14 & $2.4-30.9$ & $0.18-0.34$ & 0.00 & 0.81 & 0.96 \\
\hline IT03 Malvaccaro (2) & 8.10 & 0.850 & 23 & $3.1-23.8$ & $0.31-0.69$ & 0.00 & 0.70 & 0.88 \\
\hline IT04 Cascina Scala (2) & 11.35 & 0.650 & 32 & $4.6-53.6$ & $0.17-0.73$ & 0.00 & 0.72 & 0.93 \\
\hline IT05 Mulinu Becciu (2) & 13.34 & 0.444 & 6 & $4.0-8.6$ & $0.24-0.36$ & 0.00 & 0.71 & 0.99 \\
\hline IT06 Fossolo (2) & 40.71 & 0.748 & 9 & $2.8-87.4$ & $0.04-0.39$ & 0.00 & 1.05 & 0.88 \\
\hline IT07 Merate (2) & 21.90 & 0.420 & 31 & $1.4-62.8$ & $0.01-0.84$ & 0.15 & 0.79 & 0.92 \\
\hline IT08 Casal Palocco (2) & 28.21 & 0.380 & 10 & $3.4-50.4$ & $0.17-0.54$ & 0.00 & 0.60 & 1.08 \\
\hline CA01 Malvern (1) & 23.33 & 0.338 & 24 & $3.0-37.6$ & $0.22-0.41$ & 0.00 & 0.71 & 0.99 \\
\hline CA02 East York (1) & 155.84 & 0.393 & 13 & $1.5-24.3$ & $0.21-0.48$ & 0.15 & 0.63 & 0.96 \\
\hline US01 Pompano Beach (1) & 16.49 & 0.059 & 6 & $7.0-33.3$ & $0.04-0.18$ & 0.00 & 1.16 & 0.91 \\
\hline US02 Sample Road (1) & 22.96 & 0.186 & 6 & $6.5-57.2$ & $0.12-0.24$ & 0.50 & 0.74 & 1.01 \\
\hline DK01 Munkerisparken (1) & 6.42 & 0.318 & 8 & $2.6-14.5$ & $0.28-0.36$ & 0.00 & 0.70 & 0.98 \\
\hline FR01 Livry Gargan (1) & 253.50 & 0.326 & 38 & $1.5-28.9$ & $0.06-0.28$ & 0.10 & 0.82 & 1.00 \\
\hline GB01 Clifton Grove (1) & 10.60 & 0.403 & 19 & $1.0-6.7$ & $0.13-0.23$ & 0.00 & 0.87 & 0.94 \\
\hline GB02 St. Marks Road (1) & 7.32 & 0.456 & 14 & $2.4-13.6$ & $0.21-0.35$ & 0.00 & 0.75 & 0.97 \\
\hline HU01 Miskolc (1) & 25.24 & 0.158 & 6 & $4.3-26.0$ & $0.15-0.41$ & 0.50 & 0.62 & 1.04 \\
\hline N001 Vika (1) & 9.90 & 0.965 & 13 & $1.2-14.2$ & $0.54-0.87$ & 0.00 & 0.21 & 1.19 \\
\hline SE01 Porsoberg (1) & 13.00 & 0.397 & 7 & $1.4-11.0$ & $0.12-0.21$ & 0.20 & 0.74 & 1.03 \\
\hline YU01 Miljakovac (1) & 25.50 & 0.349 & 8 & $2.6-19.5$ & $0.13-0.25$ & 0.35 & 0.64 & 1.07 \\
\hline
\end{tabular}

If the Philip (1968) model for infiltration is adopted, the loss depth $L$, related to a storm of duration $\theta$ and characterised by rainfall intensities always higher than the infiltration velocities, can be expressed as :

$$
L(\theta)=L_{0}+S \theta^{1 / 2}+K \theta
$$

where the parameters $S$ and $K$ are the "sorptivity" and the hydraulic conductivity.

Fig. 1. Relationship between $L$ and $h$ : IT03 Malvaccaro = worst case $\left(r^{2}=0.839\right)$; SE01 Porsoberg $=$ best case $\left(r^{2}=0.999\right)$. 
IT03 Malvaccaro

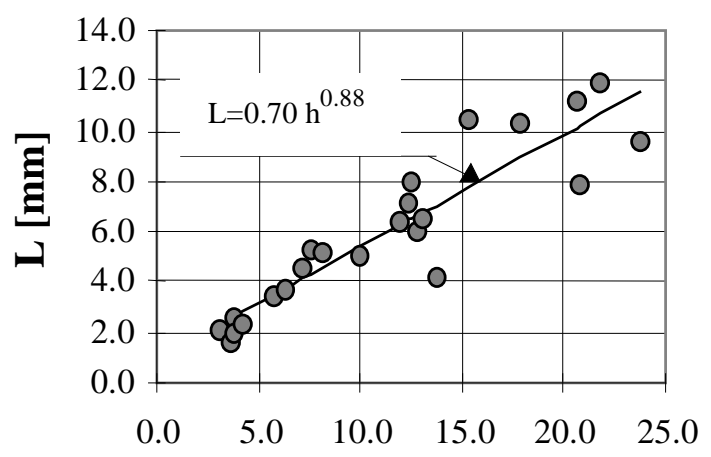

$\mathbf{h}[\mathrm{mm}]$
SE01 Porsoberg

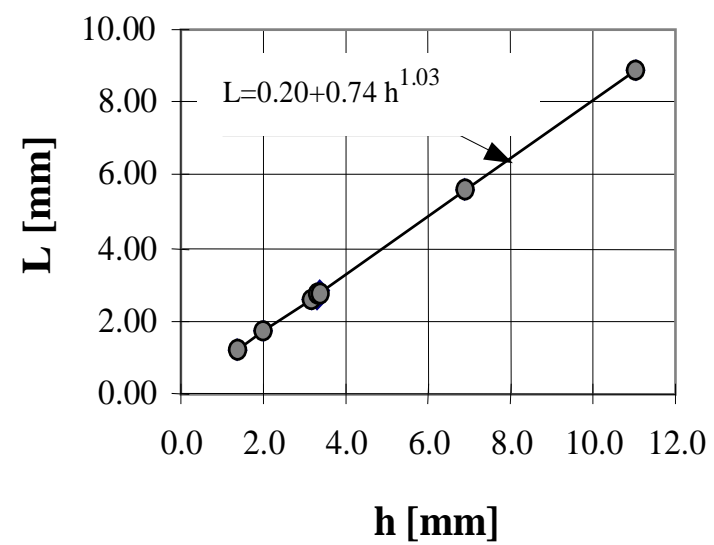

If the usual relationship between $\theta$ and $h$ of the type $h=a \theta^{n}$ is introduced, equation (4) becomes:

$L(h)=L_{0}+a^{-1 /(2 n)} S h^{1 /(2 n)}+a^{-1 / n} K h^{1 / n}$

(5)

The values of $a^{-1 / n}$ and $K$ are usually very low, so the third term is seldom relevant. Then, neglecting this term and putting $\alpha=a^{-1 /(2 n)} S$ and $\beta=1 /(2 n)$, equation (5) becomes the same as equation (3), giving, as a consequence, a theoretical justification of experimental behaviour expressed by equation (3).

As from analysis of experimental data it was seen that optimal estimates of the parameter $\beta$ range between 0.88 and 1.19 with a mean value of 0.99 (see Table 1), a linear relationship between $L$ and $h$ can be assumed $(\beta=1)$, at least in the range of the experimental data. This assumption is confirmed by the high correlation coefficients $r^{2}$ that were found, ranging from 0.839 and 0.999 with a mean value of 0.962 .

For the other parameters $L_{\mathrm{o}}$ and $\alpha$, many relationships with catchment and climatic characteristics were tested. While the parameter $L_{0}$ seemed not to be correlated with any of these characteristics, and so the mean value of $0.40 \mathrm{~mm}$ was assumed for it (mean of the values of $L_{0}$ estimated from best fitting of equation (3) with $\beta=1$ to experimental data), the parameter $\alpha$ showed a certain, even if coarse, correlation $\left(r^{2}=0.68\right)$ with the impermeability ratio Imp, finding the following regression formula

$$
\alpha=0.87-0.47 \operatorname{Imp}
$$

The system of equations (3) and (6), deriving from regression analysis, is not able, of course, to reproduce all the variability observed in the real values of the loss depth, but only to estimate its mean value. Equation (3), then, can be written more properly as

$$
\mu_{\mathrm{L}}=0.40+(0.87-0.47 \text { Imp }) h \quad[\mathrm{~mm}]
$$

In Fig. 2 the comparison between the observed values of $L$ and $\mu_{\mathrm{L}}$ for the data of all catchments is reported. A mean error of $0.017 \mathrm{~mm}$, that is near the zero value that was expected, and a standard deviation $\sigma_{\mathrm{L}}=1.79$ mm were observed.

Fig. 2. Comparison between observed and estimated (equations (3) and (6)) loss depths. 


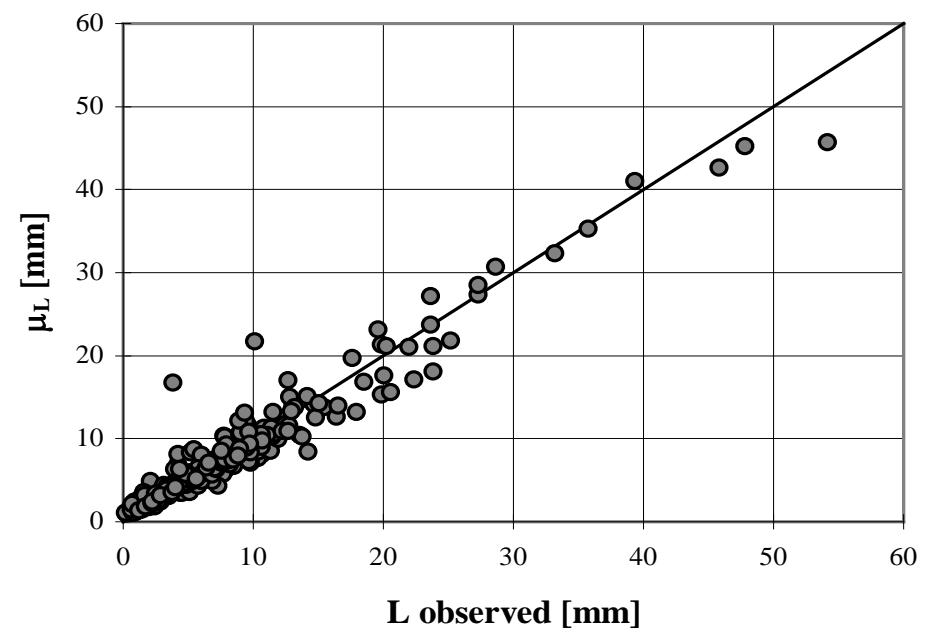

Analysing the same standard deviation separately for each catchment, values between $0.13 \mathrm{~mm}$ and 4.05 $\mathrm{mm}$ were found. These values seem to be higher for catchments characterised by intermediate values of Imp with an approximately bell-shaped trend (see fig. 3a). This could be explained by the minor heterogeneity of areas in the catchments with $\operatorname{Imp} \rightarrow 0$ and $\operatorname{Imp} \rightarrow 1$ or, more probably, by the smaller number of available data for these catchments. Waiting for a bigger amount of data to be available, a safe value, corresponding approximately to the maximum observed value, of $\sigma_{\mathrm{L}}=4 \mathrm{~mm}$ constant for all catchments is suggested to be used in design problems.

\section{ESTIMATION OF RUNOFF COEFFICIENT MOMENTS}

Given that $\varphi=1-L / h$, its mean value can be derived from equation (7) as

$$
\mu_{\varphi}=0.13+0.47 \operatorname{Imp}-\frac{0.40}{h} \quad[\mathrm{~mm}]
$$

Adopting the same procedure used for $L$, the standard deviation of $\varphi$ was estimated from the data of all catchments as $\sigma_{\varphi}=0.15$. Standard deviations for each catchment range between 0.04 and 0.28 . A clear, even if coarse, correlation $\left(r^{2}=0.50\right)$ between them and $\operatorname{Imp}$ was noted, expressed in the following regression formula (see fig. 3b),

$$
\sigma_{\varphi}=0.03+0.21 \mathrm{Imp}
$$

Fig. 3. Standard deviations of a) $L$ [mm] ; b) $\varphi$ and eq.(9). 


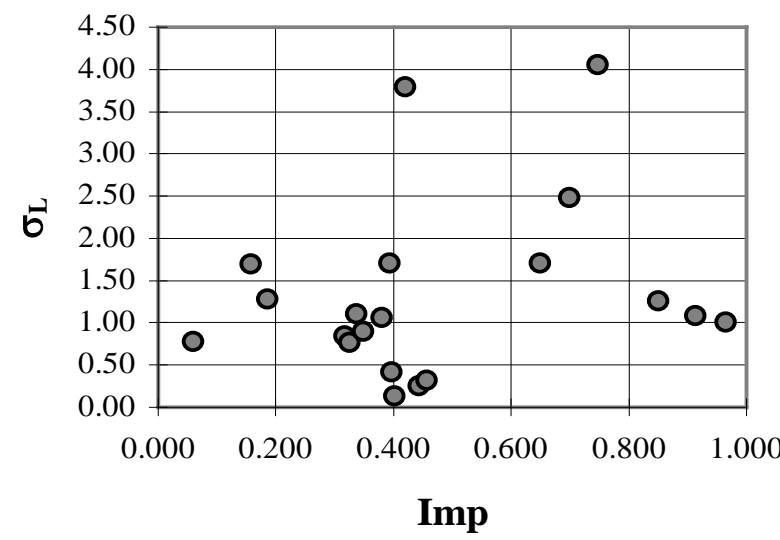

a)

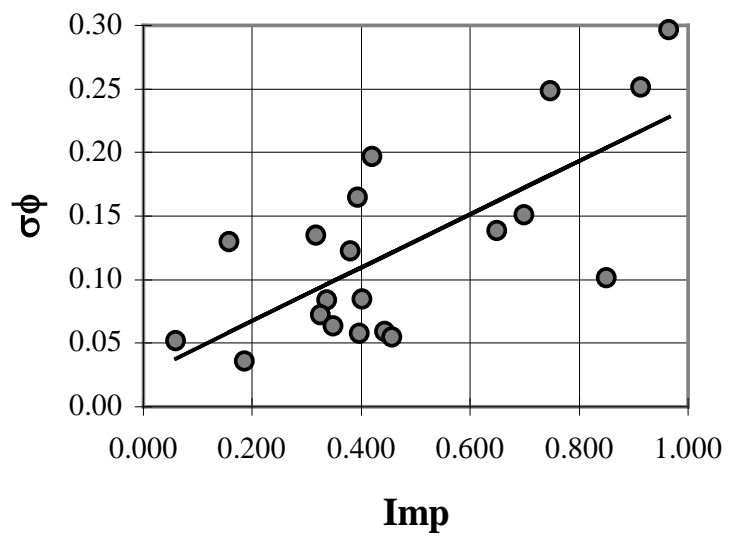

b)

\section{CONCLUSIONS}

With reference to design problems, the hydrological losses in urban catchments can be conveniently taken into account with the probabilistic approach expressed by equations (2). From the analysis of available data recorded in 20 experimental catchments all over the world, a procedure for the estimation of mean value and standard deviation of loss depth and runoff coefficient was developed. Equations (8) and (9) can be used in equations (2) for estimating $\mu_{Q}$ and $\sigma_{Q}$ if the value of $\rho_{\mathrm{i} \varphi}$ is known. Even if it is clear that $\rho_{\mathrm{i} \varphi}>0$, its evaluation is uncertain, because of the need of identifying the "significant" intensity of real hyetographs to be considered. However, it seems, according to many studies on the matter, that the value of $\rho_{\mathrm{i} \varphi}$ is usually very low. The numerical results and the procedure itself will, of course, be improved when more data from experimental catchments are available.

\section{REFERENCES}

Calomino F. and Paoletti A. (1994). Le misura di pioggia e di portata nei bacini sperimentali urbani italiani. Centro Studi Deflussi Urbani, Milano.

Kapur K.C. and Lamberson L.R. (1977). Reliability in Engineering design. Wiley.

Maksimovic C. and Radojkovic M. (1986). Urban Drainage Catchments. Pergamon Press.

Philip J.R. (1969). Theory of infiltration. In: Advances in Hydroscience, 5, pp. 216 - 296. 